\title{
Cost-benefit analysis of routine childhood vaccination against chickenpox in Taiwan: decision from different perspectives
}

\author{
Hui-Chun Hsu, Ruey Shiung Lin, \\ Tao Hsin Tung, Tony Hsiu Hsi Chen* \\ Institute of Preventive Medicine, College of Public Health, National Taiwan University, \\ Room 207, No. 19, Su-Chow, Taipei, Taiwan, ROC
}

Received 9 January 2002; accepted 27 March 2003

\begin{abstract}
Cost-benefit analysis was conducted to determine whether it is worthwhile to initiate a routine varicella vaccination program in Taiwan from different perspectives. Using the human capital approach, the discounted net cost for vaccination program was New Taiwan Dollars (NTD) 281 million from health care payer's perspective. Taking indirect costs into account, the net saving due to vaccination program was NTD 425 million from the societal perspective. In terms of benefit-cost ratio, a mass varicella vaccination program could only save NTD 0.34 in discounted costs for each dollar incurred in a vaccination program from health care payer's perspective whereas save NTD 2.06 from the societal viewpoint. Results based on the willingness-to-pay (WTP) method showed the Net Present Value (NPV) of the vaccination program was estimated as -NTD 272 million.

We conclude that a routine varicella vaccination program is worthwhile from the societal perspective but neither from health care payer's nor from consumer decision based on the perspective of WTP.
\end{abstract}

(C) 2003 Elsevier Science Ltd. All rights reserved.

Keywords: Varicella vaccination; Cost-benefit analysis; Markov Decision Model; Willingness-to-pay

\section{Introduction}

Although vaccination against chickenpox was recommended by the American Academy of Pediatrics for all healthy children older than 12 months without a history of varicella, whether a mass vaccination program is worthwhile is still highly dependent on the perspective of health economic evaluation. Earlier studies in France, Italy, New Zealand, German, Spain, and US showed that varicella vaccination was considered to be cost-effective only from the societal viewpoint but did not save money from the more restrictive perspective of health care providers [1-6]. Due to different economic levels and health care systems in different countries whether varicella vaccination is worthwhile is also contingent on whether people are willing to pay the vaccination program that would decrease the probability of chickenpox and death. Benefit due to the reduction of disease and death in cost-benefit analysis in these studies was often measured by the human capital approach for

\footnotetext{
* Corresponding author. Tel.: +886-2-23587620; fax: +886-2-23587707.

E-mail address: stony@episerv.cph.ntu.edu.tw (T.H.H. Chen).
}

which the value of vaccination program is measured by its effect on the patient's lifetime earnings. Rarely was addressed the willingness-to-pay (WTP) method that expresses the value of vaccination program by saying how much people would be willing to pay for the varicella vaccination program in order to reduce chickenpox and further death.

Taiwan has not yet included mass vaccination against chickenpox under state-run childhood immunization schedule such as measles and rubella. Except some counties that have provided a small-scale and free-charge vaccination program for children that under 6 years of age, most individuals received the vaccination from their general practitioners on the basis of private money. Since the government is in a dilemma about whether it is necessary to extend these small-scale programs into a nationwide program, it is timely to assess whether the benefit as a result of reducing deaths and long-term disability due to chickenpox can outweigh the cost invoked by vaccination program. The purpose of this study is therefore to perform cost-benefit analysis to determine whether it is worthwhile to launch mass varicella vaccination program for healthy children at age of 15 months in Taiwan from different perspectives. 


\section{Materials and methods}

\subsection{Markov Decision Model}

A decision analysis using the Markov Decision Model (Fig. 1) was constructed to compare varicella vaccination strategy with no vaccination [7]. In the non-vaccinated group, subjects followed the disease natural history as follows: subjects are infected with chickenpox and may or may not develop into symptomatic cases after around 2-week incubation period. The probability of being symptomatic cases was approximately $90 \%$. Of these symptomatic cases, the majority subjects were mild disease and few have severe complications. Those with mild disease may undergo four possible utilizations, emergency department visit (seek medical care within first $24 \mathrm{hr}$ ), emergency department visit together with subsequent outpatient visit, outpatient visits, outpatient visit plus over-counter medicine (OTC) purchase. Severe complications were defined as those requiring hospitalization, including but not limited to pneumonia and encephalitis. Patients with major complications could go on to have no long-term sequelae, long-term disability, or death.

Transition probabilities for the disease natural history of chickenpox and complications were derived from published paper $[4,6,8,9]$. Estimates in these studies, which took account of heterogeneity in the risk of transmission and contraction of infection according to the individual's age group,
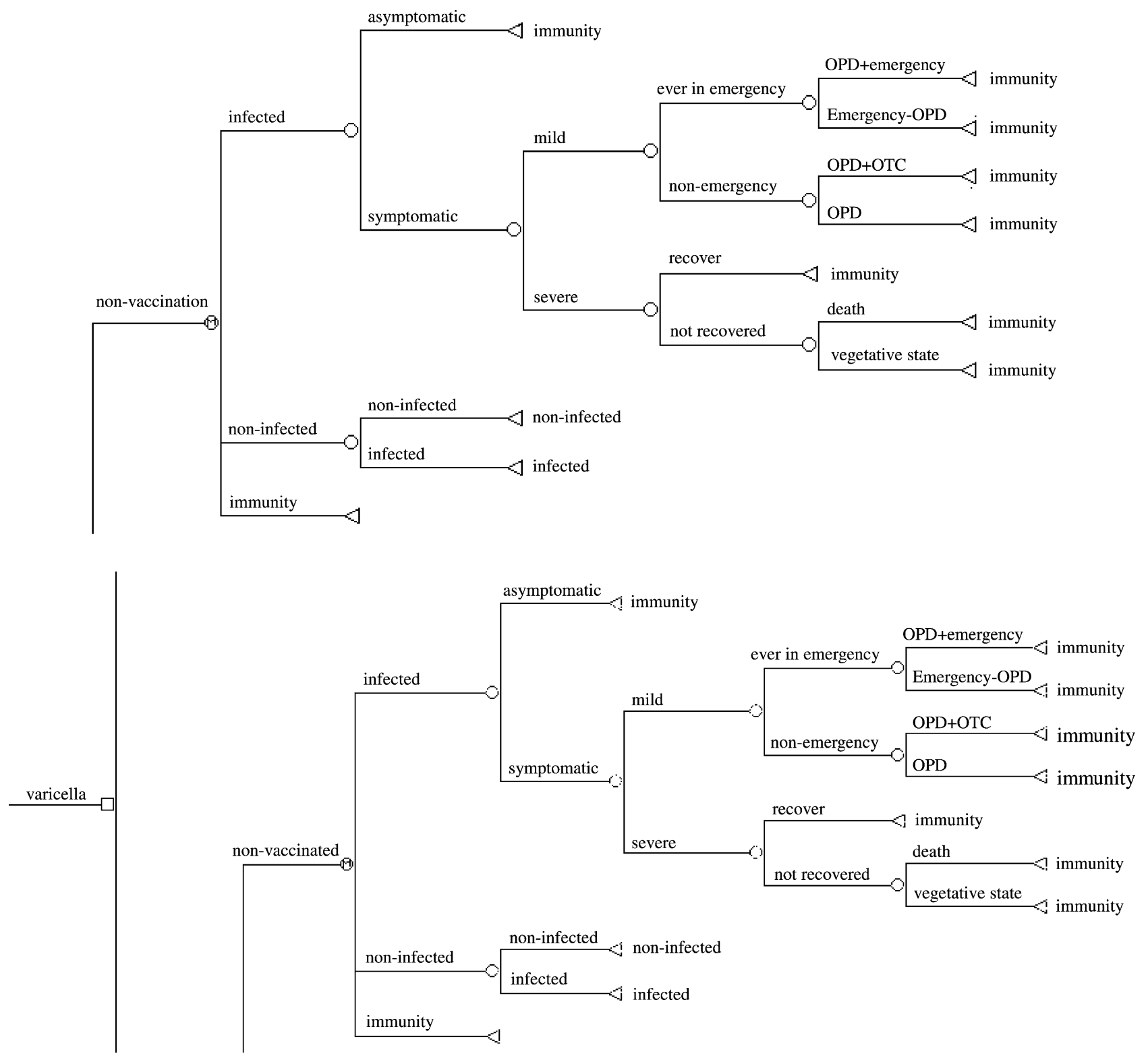

Fig. 1. Markov Decision Model for two options, vaccination and non-vaccination. 


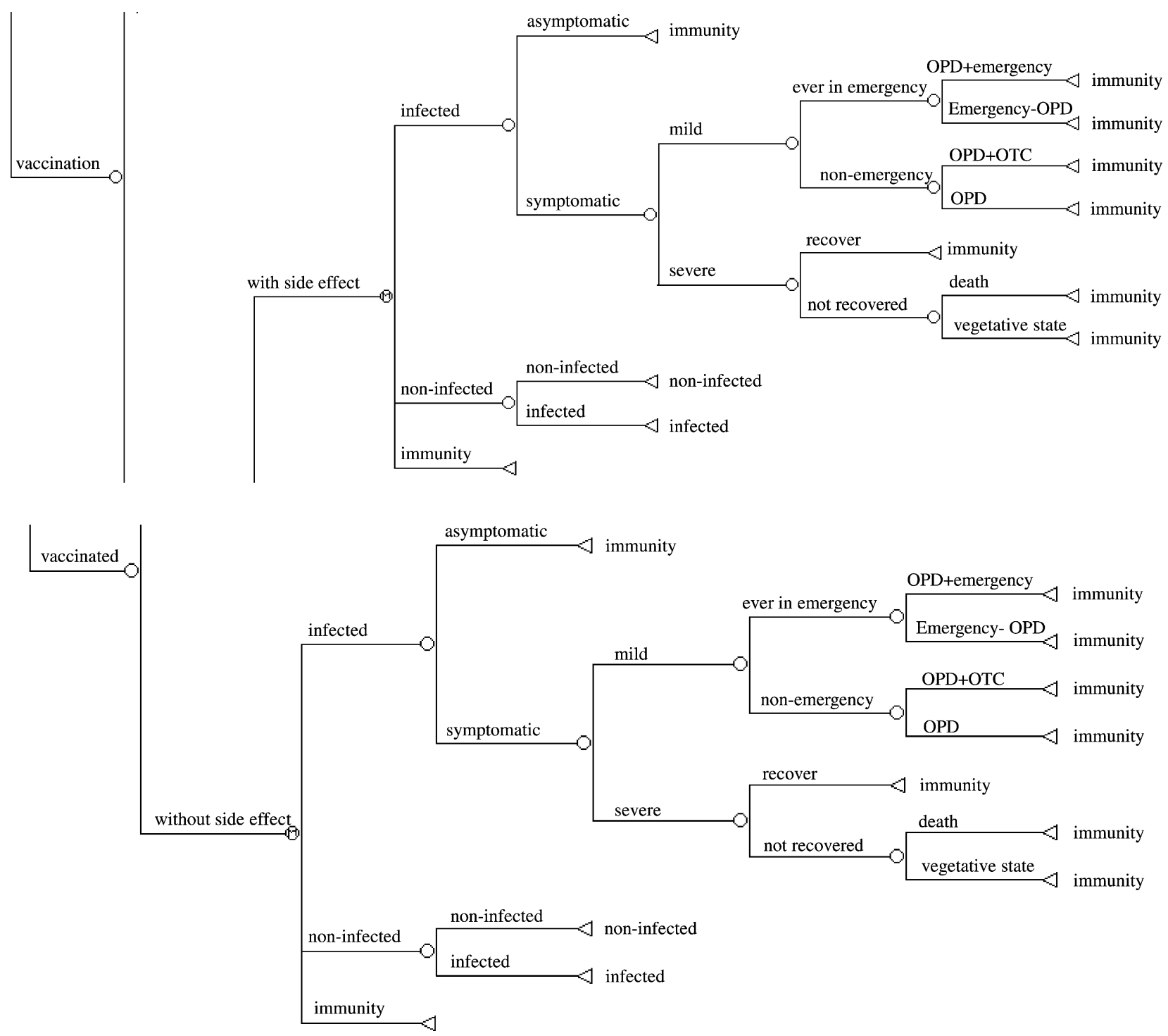

Fig. 1. (Continued).

enabled one to simulate the infection rate and attack rate by age in the unvaccinated group. The application of vaccine efficacy in reducing infectiousness and lowering susceptibility to chickenpox and the possibility of waning effect to the unvaccinated group yielded the changed parameters as a result of vaccination. For each scenario, we then calculated the expected number of cases of chickenpox under a hypothetical cohort of 300,000 population and varicella-related probabilities from 0 to 20 years old, when more than $85 \%$ of cases of chickenpox occurred in our country [10]. Table 1 showed base case estimates, the range of best and worst estimates, and resources.

\subsection{An empirical survey for direct cost, indirect cost, and the estimate of WTP}

A cross-sectional survey was conducted to interview a total of 188 varicella cases that were sampled from lo- cal general practitioners and pediatricians scattered over northern, central, southern, and eastern areas of Taiwan between October 2000 and February 2001. Information provided in this survey included the numbers of children who had had chickenpox; days absent from school, days of work leave of parents or other family members, days staying at home, times of visits, time and money incurred in visits, and monthly incomes of parents or families who could not work due to care for patient. Two types of costs were studied. Direct costs included out-of-pocket expenses as well as the value of medical resource usages. Most costs spent in varicella were outpatient and emergency visits, which was calculated by multiplying average patient's visits by medical costs (data provided by National Health Insurance (NHI)). As regards hospitalizations, a total of 87 events collected from two teaching hospitals in the previous 1 year were used to calculate average hospitalization fees. In addition, medical utilization for OTC medicine purchased 
Table 1

Base case estimates in varicella-related probabilities and varicella vaccine efficacy parameters

\begin{tabular}{|c|c|c|c|}
\hline Variable & Base case estimate & Worst and best case estimates & Reference \\
\hline $\begin{array}{l}\text { 1. Annular attack rate } \\
0-1 \text { years old } \\
2-3 \text { years old } \\
3-5 \text { years old } \\
5-7 \text { years old } \\
7-11 \text { years old } \\
11-15 \text { years old } \\
15-20 \text { years old }\end{array}$ & $\begin{array}{l}0.05 \\
0.03 \\
0.16 \\
0.13 \\
0.22 \\
0.01 \\
0.04\end{array}$ & Upper and lower $50 \%$ & Beutels et al. [4], Lin et al. [8] \\
\hline $\begin{array}{l}\text { 2. Varicella sequelae (rate per chickenpox case) } \\
\text { Major complications requiring hospitalization } \\
\text { Pneumonia } \\
\text { Encephalitis } \\
\text { Death } \\
\text { Long-term disability after encephalitis }\end{array}$ & $\begin{array}{l}0.0045 \\
0.00014 \\
0.00014 \\
0.0000082 \\
0.00000042\end{array}$ & $\begin{array}{l}0.0015-0.0054 \\
0.0015-0.0054\end{array}$ & $\begin{array}{l}\text { Choo et al. [9] } \\
\text { Lieu et al. [6] } \\
\text { Lieu et al. [6] } \\
\text { Lieu et al. [6] } \\
\text { Lieu et al. [6] }\end{array}$ \\
\hline $\begin{array}{l}\text { 3. Vaccine efficacy parameters } \\
\text { Complete protection after vaccination } \\
\text { Immunity in partial by age of } 20 \text { years } \\
\text { Relative susceptibility to varicella } \\
\text { Relative infectiousness } \\
\text { Relative probability of major sequelae }\end{array}$ & $\begin{array}{l}0.95 \\
0.22 \\
0.12 \\
0.4 \\
0.01\end{array}$ & $\begin{array}{l}0.83-0.95 \\
0.05-0.30 \\
0.05-0.16 \\
0.0-0.95 \\
-\end{array}$ & $\begin{array}{l}\text { Lieu et al. [6] } \\
\text { Lieu et al. [6] } \\
\text { Lieu et al. [6] } \\
\text { Lieu et al. [6] } \\
\text { Lieu et al. [6] }\end{array}$ \\
\hline $\begin{array}{l}\text { 4. Vaccination complication rate } \\
\text { 5. Asymptotic rate } \\
\text { 6. Coverage rate } \\
\text { 7. Vaccine price } \\
\text { 8. Discount rate }(\%)\end{array}$ & $\begin{array}{l}0.02 \\
0.10 \\
0.95 \\
1500 \\
5\end{array}$ & $\begin{array}{l}0.01-0.05 \\
0.05-0.20 \\
0.75-0.97 \\
1500-3000 \\
3-8\end{array}$ & $\begin{array}{l}\text { Lieu et al. [6] } \\
\text { Lieu et al. [6] } \\
\text { CDC } \\
\text { Lieu et al. [6] } \\
-\end{array}$ \\
\hline
\end{tabular}

was also collected in our survey and only four individuals had used. Indirect costs were defined as the value of productivity loss because of disease. The capital approach was applied to calculate the cost of work loss by multiplying each adult's loss of working days by his or her daily income.

Since varicella vaccine was administered with the MMR vaccine in our scenario, there were no additional physician consultation fees and cost induced by varicella vaccine administration. The cost of varicella vaccine was determined by using as a reference the price of this vaccine in US and local practitioners in Taiwan (New Taiwan Dollars (NTD) 1500 in the base case). Approximately 2\% of vaccinated persons have suffered from pain at the injection side and rash and required one additional follow-up outpatient visit for treatment of these minor complications [6]. The estimate of WTP was measured by the following question: "what is the most that you would be willing to pay for routine varicella vaccination program that reduce the risk of death and long-term disability as shown in Table 1 ?

\subsection{Cost-benefit analysis}

All costs were expressed as NTD. Costs and benefits were discounted to present value at 5\%. Using the capital approach, discounted net cost (saving) for the vaccination pro- gram, taking direct costs or indirect costs into account, was calculated. Benefit-cost ratios were calculated as the reduction disease costs divided by the cost of the vaccination program. Using the willingness-to-pay approach, Net Present Value (NPV) was also calculated on the basis of the total benefit (calculated by the WTP method) minus total cost for the vaccination program. A series of sensitivity analyses were conducted to assess the uncertainty of relevant parameters.

\section{Results}

Of the 188 eligible cases, 10 subjects refused to participate in this study. Only 178 cases completed the interview with 94\% (178/188) response rate. Table 2 showed average unit/rate per case, average cost per unit/rate for calculating direct cost and indirect cost, and the estimate of WTP. It should be noted that the hospitalization rate and complication rate were derived from Yawn et al. [10].

Table 3 showed total discounted direct costs and indirect costs using the human capital approach. Vaccination program could save NTD 147 million in discounted direct costs. From health care payer's perspective, the discounted net cost for vaccination program was NTD 281 million. The discounted indirect cost saved by vaccination program was estimated at NTD 733 million. This yields NTD 452 
Table 2

Estimates of variable related to direct cost and indirect cost, and willingness-to-pay for varicella vaccination

\begin{tabular}{|c|c|c|c|}
\hline Events & $\begin{array}{l}\text { Average } \\
\text { unit/rate } \\
\text { per case }\end{array}$ & $\begin{array}{l}\text { Cost per } \\
\text { unit } \\
\text { (NTD) }\end{array}$ & $\begin{array}{l}\text { Average cost } \\
\text { per case } \\
(\mathrm{NTD})\end{array}$ \\
\hline \multicolumn{4}{|l|}{ 1. Direct cost } \\
\hline OPD & 1.8 visits & 450 & 810 \\
\hline ER & 0.016 visits & 750 & 12 \\
\hline OTC & 0.022 times & 204 & 4.5 \\
\hline Hospitalization rate & $0.0054^{\mathrm{a}}$ & 17442 & 94 \\
\hline Long-term disability & $0.0000042^{\mathrm{a}}$ & 6595238 & 27.7 \\
\hline \multicolumn{4}{|l|}{ 2. Indirect cost } \\
\hline Visiting time & $48.6 \mathrm{~min}$ & 3.5 & 170 \\
\hline Work loss & 1.85 days & 1891 & 3500 \\
\hline $\begin{array}{l}\text { Accompanied in } \\
\text { hospitalization }\end{array}$ & $0.0054^{\mathrm{a}}$ & 3222 & 17.4 \\
\hline $\begin{array}{r}\text { Death and long-term } \\
\text { disability adjusted }\end{array}$ & $0.0000124^{\mathrm{a}}$ & 5513459 & 68.4 \\
\hline 3. Willingness-to-pay & - & - & 729 \\
\hline
\end{tabular}

million net saving due to vaccination program from the societal perspective. A varicella vaccination program could save NTD 2.06 from the societal viewpoint but only save NTD 0.34 in discounted costs for each NTD dollar incurred in a vaccination program from health care payer's perspective.

The average estimate of WTP in order to reduce major sequelae as shown in Table 1 was NTD 729. Translating this figure into benefit yields NTD 220 million benefit due to vaccination program. The NPV of the program, taking indirect cost into account, was -NTD 272 million.

In order to examine the uncertainty derived from published and/or unpublished data, a series of one-way sensitivity analyses were conducted on a number of key model variables. Table 4 showed the threshold value of sensitivity analysis. It could be seen that the program cost-effectiveness was highly sensitive to vaccine price and insensitive to vaccine efficacy in plausible range. The threshold value under

Table 3

Cost-benefit analysis using the human-capital approach

\begin{tabular}{llrl}
\hline $\begin{array}{l}\text { Discounted costs } \\
\text { (NTD in million) }\end{array}$ & $\begin{array}{l}\text { No } \\
\text { vaccination }\end{array}$ & Vaccination & $\begin{array}{l}\text { Net cost (saving) } \\
\text { of no vaccination } \\
\text { vs. vaccination }\end{array}$ \\
\hline $\begin{array}{l}\text { Direct cost } \\
\quad \text { Vaccine }\end{array}$ & 0 & 428 & 428 \\
$\quad \begin{array}{l}\text { Varicella disease } \\
\quad \text { costs }\end{array}$ & 203 & 56 & $(147)$ \\
$\quad \begin{array}{l}\text { Total } \\
\text { Indirect cost }\end{array}$ & 203 & 484 & 281 \\
$\begin{array}{l}\text { Total (direct cost } \\
\quad \text { indirect cost) }\end{array}$ & 944 & 8 & $(733)$ \\
\hline
\end{tabular}

Payer's perspective benefit-cost ratio estimate: $147 / 428=0.34$. Societal perspective benefit-cost ratio estimate: $(733+147) / 428=2.06$.
Table 4

Sensitivity analysis for relevant parameters

\begin{tabular}{lcll}
\hline Variable & $\begin{array}{l}\text { Base-case } \\
\text { estimate }\end{array}$ & Range & Threshold \\
\hline Annual attack rate ratio & 1 & $0.05-1.5$ & 0.28 \\
Asymptotic rate & 0.1 & $0-0.9$ & 0.56 \\
Coverage rate & 0.95 & $0-1$ & Dominated \\
Discounting rate & 0.05 & $0-0.08$ & Dominated \\
Vaccine efficacy ratio & 1 & $0.6-1.4$ & Dominated \\
Herd immunity effect & 0.6 & $0-1$ & Dominated \\
Mild disease rate in vaccinee & 0.9955 & $0-1$ & Dominated \\
Adverse rate after vaccination & 0.02 & $0-1$ & Dominated \\
Severe disease rate in vaccinee & 0.000045 & $0-1$ & 0.94 \\
Vaccine cost & 1500 & $1500-4000$ & 3093 \\
Symptomatic rate of vaccinee & 0.108 & $0-1$ & Dominated \\
\hline
\end{tabular}

which vaccine began to save money from the societal perspective was NTD 3093.

\section{Discussion}

\subsection{Decision from different perspectives}

The present study used cost-benefit analysis to assess whether a varicella vaccination program against nonvaccination group is worthwhile in Taiwan from different perspectives. The results show indirect costs play an important role in the evaluation of the varicella vaccination program. Vaccination program could save NTD 733 million in discounted indirect costs compared with only NTD 147 million in discounted direct cost associated with varicella disease costs. From health care payer's perspective, the discounted net cost for vaccination program was NTD 281 million. This suggests that the benefit from the vaccination program cannot outweigh the cost incurred in the vaccination program from health care payer's perspective. Taking indirect cost into account, the NTD 452 million net saving suggest the varicella vaccination program is rather worthwhile from the societal perspective.

Using the WTP approach, the present study shows it is not worthwhile to have vaccination from the perspective of WTP due to the negative NPV value. It should be noted that the WTP approach is a contingent-valuation method that reflects consume surplus of getting varricella vaccination. Since the mean estimate of WTP (NTD 729) for the vaccination program was far below the current expense for vaccination (NTD 1500) this suggests that they could not get any surplus from the purchase of vaccination. This accounts for why the result of NPV is negative. If the estimate of WTP is raised to NTD 2000, this means that if people have to pay only NTD 1500 for benefits they value at NTD 2000 then they get a surplus of NTD 500 from the purchase of vaccination. Results from the WTP suggest that the amount people in this country are willing to pay for the program is lower than the benefit they value. In term of consumer decision based on the perspective of WTP, it may not be worthwhile to launch a mass vaccination. 


\subsection{Comparison with earlier studies}

Our benefit-cost ratio was 0.34 from health care payer's perspective. This estimate is lower than 0.9 from Lieu et al. [6], 0.82 from Beutel et al. [4], and 0.67 from Scuffham et al. [3], but closer to 0.39 from Huse et al. [11]. From the societal perspective, our benefit-cost ratio was 2.06 , which is also lower than 5.4 from Lieu et al. [6], 4.6 from Beutel et al. [4], and 2.79 from Scuffham et al. [3], but still closer to 2.45 from Huse et al. [11]. The first reason for this difference is that annual attack rates adopted in this study were age-specific and may be lower than other studies. The second reason may be due to different study designs and different medical usage in the treatment of chickenpox across countries. The most prominent discrepancy was in indirect costs, there was 10 times between vaccination and non-vaccination in US [6], but only 9 times in our studies, indicating higher productivity loss in highly industrialized countries. However, it still saved NTD 2 for every dollar invested in the program.

\subsection{Limitation}

There are some critiques raised from our study. Firstly, it is important to note that, from an epidemiological perspective, it is not possible to predict all of the long-term effects of varicella vaccination on immunity alternations and disease variations. There are complex and unresolved issues regarding the possibility of the immunity conferred by the vaccine waning over time. This might be due to some uncertainty about the duration of time over which immunity is conferred following vaccination compared to the life-long immunity that follows infection with the wild VZV. Besides, there is another possibility that, as routine vaccination eventually causes the disease to become rare, this in itself reduces the long-term protection conferred by initial immunization. These possibilities arise as there would be fewer 'natural' opportunities for 'boosting' immunity by exposure to the wild virus in the community. Both of above possibilities may, in the future, increase the cost per case of chickenpox infection with a vaccination program in place. This concern should be clarified in the ongoing research. Secondly, our results are conditional on attaining optimal coverage rate and the vaccine being administrated in conjunction with MMR vaccine. Otherwise, a 95\% coverage rate will not be attained, and the costs of vaccination program might not be as low as estimated. This is rather important, since low coverage rate will not only produce baleful consequences for the economic results but could also lead to a shift of infections to older age groups, creating a large pool of older susceptible persons who are at risk of more severe varicella. Therefore, to reduce the possibility of a large number of sero-negative adults in the future and the potential danger of infection shifts to older age group, it is necessary to immunize the maximum possible number of children, and to consider booster doses for adults or 'catch-up' program at age of 12. However, whether 'catch-up' program is cost-effective should be elucidated in the future. Thirdly, we did not attempt to include the potential benefits or costs of future cases of zoster. Zoster may be clinically mild in vaccinated healthy persons than in unvaccinated persons, because there were limited data on the long-term incidence of zoster in vaccinated persons [12-14].

In conclusion, the present study suggests that a routine varicella vaccination program is worthwhile from the societal perspective but neither from health care payer's perspective nor from consumer decision based on the perspective of WTP.

\section{References}

[1] Coudeville L, Paree F, Lebrum T, Sailly JC. The value of varicella vaccination in healthy children: cost-benefit analysis of the situation in France. Vaccine 1999;17:142-51.

[2] Fornaro P, Gandini F, Marin M, Pedrazzi C, Piccoli P, Tognetti D, et al. Epidemiology and cost analysis of varicella in Italy: results of a sentinel study in the pediatric practice. Pediatr Infect Dis J 1999;18:414-9.

[3] Scuffham P, Devlin N, Eberhart-Philips J, Wilson-Salt R. The cost-effectiveness of introducing a varicella vaccine to the New Zealand immunization schedule. Social Sci Med 1999;49:763-79.

[4] Beutels P, Clara R, Tormans G, Doorslaer V, Van Damme P. Costs and benefits of routine varicella vaccination in German children. $J$ Infect Dis 1996;174(Suppl 3):S335-41.

[5] Diez Domingo J, Ridao M, Latour J, Ballester A, Morant A. A cost-benefit analysis of routine varicella vaccination in Spain. Vaccine 1999;17:1306-11.

[6] Lieu TA, Cochi SL, Black SB, Halloran ME, Shinefield HR, Holmes $\mathrm{SJ}$, et al. Cost-effectiveness of a routine varicella vaccination program for US children. J Am Med Assoc 1994;271:375-81.

[7] Sonnenberg FA, Beck JR. Markov models in medical decision making: a practical guide. Med Decis Making 1993;13:322-38.

[8] Lin YJ, Huang LM, Lee CY, Chih TW, Lee PL, Chang LY, et al. A seroepidemiological study of varicella-zoster virus in Taipei city. Acta Pediatr Sin 1996;37:11-5.

[9] Choo PW, Donahue JG, Manson JE, Platt R. The epidemiology of varicella and its complications. J Infect Dis 1995;172:706-12.

[10] Yawn BP, Yawn RA, Lydick E. Community impact of childhood varicella infections. J Pediatr 1997;130:759-65.

[11] Huse DM, Meissner HC, Lacey MJ, Oster G. Childhood vaccination against chickenpox: an analysis of benefits and costs. J Pediatr 1994;124:869-74.

[12] Hardy I, Gershon AA, Steinberg SP, LaRussa P, and the Varicella Vaccine Collaborative Study Group. The incidence of zoster after immunization with live attenuated varicella vaccine. $\mathrm{N}$ Engl J Med 1991;325:1545-50.

[13] Brunell PA, Taylor-Wiedeman J, Geiser CF, Frierson L, Lydick E. Risk of herpes zoster in children with leukemia: varicella vaccine compared with history of chickenpox. Pediatrics 1986;77:53-6.

[14] Lawrence R, Gershon AA, Holzman R, Steinberg SP, and the NIAID Varicella Vaccine Collaborative Study Group. The risk of zoster after varicella vaccination in children with leukemia. N Engl J Med 1988;318:543-8. 